Ilchmann, Achim:

High-gain adaptive control: an overview

Aus:

Adaptive control : colloquium, Thursday, 13 June 1996 / organised by Professional Group C8 (Control systems theory and design), IEE Computing and Control Division ...- London : IEE, 1996 (Colloquium Digest / IEE 1996/139), S. 1/1-1/4 


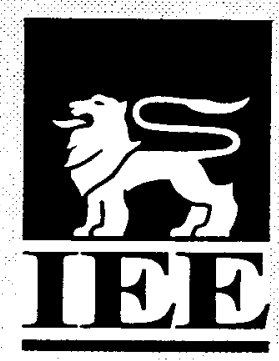

\section{COMPUTING AND CONTROL DIVISION}

\section{ADAPTIVE CONTROL}

Colloquium organised by

Professional Group C8 (Control systems theory and design) in association with the Institute of Measurement and Control

Thursday, 13 June 1996

Digest No: 96/139 


\title{
High-gain adaptive control: an overview
}

\author{
Achim Ilchmann \\ Department of Mathematics, University of Exeter, U.K.
}

A wide range of control theory deals with the problem that, for a known plant, a controller has to be designed in order that the feedback system achieves a prespecified control objective. The fundamental difference between this approach and that of adaptive control is that the plant is not known exactly, only structural information is available. The aim is therefore to design a single controller which can be applied to a variety of systems belonging to a certain class. The control law has to be designed so that the controller learns form the behaviour of the system, and based on this information, it adjusts its parameters. This area has been intensively studied over the last 40 years. See $[1,32]$ for survey articles.

Up to the end of the 1970s, most adaptive control mechanisms would attempt to identify or to estimate certain parameters of the plant, and then design a feedback controller on the basis of this information. Here an overview is given on adaptive controllers which are not based on any parameter identification or estimation algorithm, see also [10]. The objective is not to obtain information about the plant, but simply to control the unkown plant or process.

We consider the class of linear, time-invariant systems of the form

$$
\left.\begin{array}{rl}
\dot{x}(t) & =A x(t)+B u(t) \quad, x(0)=x_{0} \\
y(t) & =C x(t)
\end{array}\right\}
$$

where

(i) $(A, B, C) \in \mathbb{R}^{n \times n} \times \mathbb{R}^{n \times m} \times \mathbb{R}^{m \times n}$ and $n$ are unknown,

(ii) $(A, B, C)$ is stabilizable and detectable,

(iii) $C\left(s I_{n}-A\right)^{-1} B$ has no zeros in $\{s \in \mathbb{C} \mid$ Res $\geq 0\}$,

(iv) $\sigma(C B) \subset\{s \in \mathbb{C} \mid$ Res $>0\}$ [or $\operatorname{det} C B \neq 0$ ].

If output feedback of the form

$$
u(t)=-k y(t)
$$

is applied, then we obtain a closed-loop system

$$
\dot{x}(t)=[A-k B C] x(t) \quad, x(0)=x_{0} .
$$

Assumption (ii) guarantees that the unstable modes can be controlled and observed. (iii) is essentially a generalization of the minimum phase condition to multivariable systems. In other words, the zero dynamics are exponentially stable. Thus for $k$ tending to $+\infty$ the poles of (2) tend to the zeros of (1) and the remaining poles go off to infinity. Finally, (iv) ensures that the remaining poles tend to $-\infty$. (A modified feedback has to be applied if the weaker assumption $\operatorname{det} C B \neq 0$ holds true.) 
So far the system will be asymtotically stable for $k$ 'large enough'. However $k$ has to be found adaptively. In the seminal work of $[29,33,41]$ the following simple adaptive control strategy has been introduced

$$
\left.\begin{array}{l}
u(t)=-k(t) y(t) \\
\dot{k}(t)=\|y(t)\|^{2} \quad, k(0)=k_{0} \in \mathbb{R} .
\end{array}\right\}
$$

Now the time-varying gain $k(t)$ is increasing as long as $\dot{x}(t)=[A-k(t) B C] x(t)$ is unstable. Until finally the system becomes stable, $k(t)$ converges to a finit limit, and $x(t)$ tends to 0 .

This simple adaptive control strategy (with slight modifications) is universal in the sense that it works for whole classes of minimum phase systems. It is the underlying idea for many generalizations of the class (i)-(iv) and many different control objectives. To name but a few references: Linear systems: $[2,12,13,15,25,26,33,41]$

Infinite dimensional systems: $[5,6,19,21,22,23,24]$

Nonlinear systems: $[16,18,35,36,37,38]$

Robustness: $[7,20,23,27,34]$

Perfopirmance: $[9,12,27]$

Higher relative degree: $[3,4,10,17,27,30,31]$

Stability of the final system: $[11,14]$

Tracking $[8,16,21,25,27,28,29,40]$

\section{References}

[1] Åström, K.J. (1987) Adaptive feedback control, Proceedings of the IEEE 75, 185-217

[2] Byrnes, C.I. and J.C. Willems (1984) Adaptive stabilization of multivariable linear systems, Proc. 23rd Conf. on Decision and Control, Las Vegas, 1574-1577

[3] Corless, M. (1988) First order adaptive controllers for systems which are stabilizable via high gain output feedback, pp. 13-16 in Analysis and Control of Nonlinear Systems (C.I. Byrnes, C.F. Martin and R.E. Seaks, eds.), Elsevier Science Pubs., North-Holland

[4] Corless, M. (1991) Simple adaptive controllers for systems which are stabilizable via high gain feedback, IMA Journal of Math. Control and Information 8, 379-387

[5] Dahleh, M. (1989) Generalizations of Tychonov's theorem with applications to adaptive control of SISO delay systems, Syst. Control Lett. 13, 421-427

[6] Dahleh, M. and W.E. Hopkins, Jr. (1986) Adaptive stabilization of single-input single-output delay systems, IEEE Trans. Aut. Control 31, 577-579

[7] Helmke, U. and D. Prätzel-Wolters (1988) Robustness properties of universal adaptive stabilizers for first order systems, Int. J. Control 48, 1153-1182

[8] Helmke, U., D. Prätzel-Wolters and S. Schmid (1990) Adaptive tracking for scalar minimum phase systems, pp. 101-118 in Control of Uncertain Systems (D. Hinrichsen and B. Mårtensson, eds.), Boston, Birkhäuser

[9] Heymann, M., J.H. Lewis and G. Meyer (1985) Remarks on the adaptive control of linear plants with unknown high-frequency gain, Syst. Control Lett. 5, 357-362

[10] Ilchmann, A. (1991) Non-identifier-based adaptive control of dynamical systems: a survey. IMA Journal of Math. Control and Inf. 8, 321-366

[11] Ilchmann, A. (1994) Adaptive controllers and root-loci of minimum phase systems, Dynamics and Control 4, 123-146

[12] Ilchmann, A. (1993) Non-Identifier-Based High-Gain Adaptive Control, Lecture Notes in Control and Information Sciences 189, Springer-Verlag, Berlin Heidelberg 
[13] Ilchmann, A. and H. Logemann (1992) High-gain adaptive stabilization of multivariable linear systems - revisited, Syst. Control Lett. 18, 355-364

[14] Ilchmann, A. and D.H. Owens (1991) Exponential stabilization using piecewise constant gain adaptation, Proc. 30-th IEEE Conf. on Decision and Control, Brighton, 83-84

[15] Ilchmann, A., D.H. Owens and D. Prätzel-Wolters (1987) High gain robust adaptive controllers for multivariable systems, Syst. Control Lett. 8, 397-404

[16] Ilchmann, A. and E.P. Ryan (1994) Universal $\lambda$-tracking for nonlinearly-perturbed systems in the presence of noise, Automatica 30, 337-346

[17] Ilchmann, A. and S. Townley (1993) Simple adaptive stabilization of high-gain stabilizable systems, Syst. Control Lett. 20, 189-198

[18] Khalil, H.K. and A. Saberi (1987) Adaptive stabilization of a class of nonlinear systems using high-gain feedback, IEEE Trans. Aut. Control 32, 1031-1035

[19] Kobayashi, T. (1987) Global adaptive stabilization of infinite-dimensional systems, Syst. Control Lett. 9, 215-223

[20] Logemann, H. (1990) Adaptive exponential stabilization for a class of nonlinear retarded processes, Mathematics of Control, Signals, and Systems 3, 255-269

[21] Logemann H. und A. Ilchmann (1994) An adaptive servomechanism for a class of infinitedimensional systems, to appear in SIAM J. on Contr. 32

[22] Logemann, H. and B. Mårtensson (1992) Adaptive stabilization of infinite-dimensional systems, IEEE Trans. Aut. Control 37, 1869-1883

[23] Logemann, H. and D.H. Owens (1988) Input-output theory of high-gain adaptive stabilization of infinite dimensional systems with nonlinearities, Int. J. Adap. Control and Signal Processing 2, 193-216

[24] Logemann, H. and H. Zwart (1991) Some remarks on adaptive stabilization of infinite-dimensional systems, Syst. Control Lett. 16, 199-207

[25] Mareels, I. (1984) A simple selftuning controller for stably invertible systems, Syst. Control Lett. $4,5-16$

[26] Mårtensson, B. (1986) Adaptive stabilization; Thesis, Lund Institute of Technology, Lund, Sweden

[27] Miller, D.E. and E.J. Davison (1991) An adaptive controller which provides an arbitrarily good transient and steady-state response, IEEE Trans. Aut. Control 36, 68-81

[28] Miller, D.E. and E.J. Davison (1992) An adaptive tracking problem, Int. J. Adap. Control and Signal Processing 6, 45-63

[29] Morse, A.S. (1984) An adaptive control for globally stabilizing linear systems with unknown high-frequency gains, pp. 58-68 in Lect. Notes Control Inf. Sci. 62, Springer-Verlag, Berlin

[30] Morse, A.S. (1986) Simple algorithms for adaptive stabilization, in: Proc. ISSA, Conf. on Modelling and Adaptive Control, Sopron, Hungary, and pp. 254-264 in Lect. Notes Control Inf. Sci. 105, Springer-Verlag, Berlin,(1988)

[31] Morse, A.S. (1987) A 4(n+1)-dimensional model reference adaptive stabilizer for any relative degree one or two, minimum phase system of dimension $\mathrm{n}$ or less, Automatica 23, 123-125

[32] Narendra, K.S. (1991) The maturing of adaptive control, pp. 3-36 in Lect. Notes in Control and Inf. Sciences 160, Springer-Verlag, Berlin

[33] Nussbaum, R.D. (1983) Some remarks on a conjecture in parameter adaptive control, Syst. Control Lett., 3, 243-246

[34] Owens, D.H., D. Prätzel-Wolters und A. Ilchmann (1987) Positive real structure and high gain adaptive stabilization, IMA Journal of Math. Control and Inf. 4, 167-181 
[35] Ryan, E.P. (1988) Adaptive stabilization of a class of uncertain nonlinear systems: A differential inclusion approach, Syst. Control Lett. 10, 95-101

[36] Ryan, E.P. (1991) A universal adaptive stabilizer for a class of nonlinear systems, Syst. Control Lett. 16, 209-218

[37] Ryan, E.P. (1992) Universal $W^{1, \infty}$-tracking for a class of nonlinear systems, Syst. Control Lett. $18,201-210$

[38] Saberi, A. and Z. Lin (1990) Adaptive high-gain stabilization of 'minimum-phase' nonlinear systems, Control-Theory and Advanced Technology 6, 595-607

[39] Tao, G. and A. Ioannou (1991) Robust adaptive control of plants with unknown order and high frequency gain, Int. J. Control 53, 559-578

[40] Townley, S. and D.H. Owens (1991) A note on the problem of multivariable adaptive tracking, IMA Journal of Math. Control and Information 8, 389-395

[41] Willems, J.C. and C. I. Byrnes (1984) Global adaptive stabilization in the absence of information on the sign of the high frequency gain, pp. 49-57 in Lect. Notes in Control and Inf. Sciences 62, Springer-Verlag, Berlin

(C) 1996 The Institution of Electrical Engineers.

Printed and published by the IEE, Savoy Place, London WC2R OBL, UK. 